\title{
Scopolamine and food-reinforced behavior in the rat
}

\author{
ROD PLOTNIK, SANDRA MOLLENAUER, and LEON MILBERG \\ San Diego State University, San Diego, California 92182
}

\begin{abstract}
Male hooded rats were food-deprived and trained to barpress on a fixed ratio schedule in which every 25th bar press was reinforced (FR25) with liquid food. Three 5-min nonreinforced (S $\Delta$ ) periods were imposed at the beginning, middle, and end of the session. Under the anticholinergic drug, scopolamine, the rate of barpressing did not differ significantly from control, but there was a significant delay in the onset of barpressing. Scopolamine-treated animals did not receive reinforcement until well into the FR25 period. The peripheral control drug, methyl scopolamine, did not cause a delay in the onset of barpressing. In addition, scopolamine, but not methyl scopolamine, caused a change in the topography of FR performance; the pauses typical of FR performance were frequently omitted or delayed. Finally, scopolamine, but not methyl scopolamine, caused a significant increase in the rate of barpressing during the second and third $\mathrm{S} \Delta$ periods.
\end{abstract}

Centrally active anticholinergic drugs, such as atropine and scopolamine, are frequently used in learning or discrimination experiments in which the primary reinforcer is food (Leaton \& Kreindler, 1972; Wagman \& Maxey, 1969; Whitehouse, 1964). Thus, it is important to know whether these anticholinergic drugs have an effect on food-reinforced behaviors.

On the basis of Grossman's (1962) work with direct chemical stimulation of the brain, it has generally been assumed that cholinergic mechanisms play no part in food-reinforced behavior. However, more recent work showed that direct cholinergic stimulation of the brain resulted in a decrease in feeding behavior (Singer \& Kelly, 1972). Thus, drugs that reduce central cholinergic activity might be expected to have the opposite effect; in other words, an anticholinergic drug might be expected to increase feeding behavior. In previous research with the anticholinergic drug, scopolamine, we found that scopolamine increased feeding behavior in the presence of an unconditioned aversive stimulus, but not in a free feeding situation (Plotnik, Mollenauer, $\&$ Snyder, 1974). One possible interpretation of the previous results is that the anticholinergic drug acted upon neural circuits mediating food-reinforced behavior.

The purpose of the present research was to explore the effect of the anticholinergic drug, scopolamine, on the rate of food-reinforced behavior. Prior to drug treatment, animals were food deprived and trained to barpress on a fixed-ratio schedule for liquid food. It is important to use liquid reinforcers

This research was supported in part by grants from the San Diego State University Foundation, 233006-964 and 233006-961, and from NIMH Grant MH-24329-01. in studying the effects of anticholinergic drugs since these drugs are known to suppress intake of dry food (Miczek, 1973; Schmidt, Moak, \& Van Meter, 1958; Stein, 1963; Whitehouse, 1964), presumably through their blockade of salivation (Stein, 1963).

In addition to fixed-ratio reinforcement periods, several nonreinforced $(\mathrm{S} \Delta)$ periods were interspersed throughout the session. These $S \Delta$ periods were used because $S \Delta$ performance has previously been shown to be sensitive to scopolamine; animals treated with scopolamine show increased responding through the $\mathrm{S} \Delta$ period (Carlton, 1969; Herrnstein, 1958). Thus, increased responding through these periods would indicate effective doses of scopolamine. Methyl scopolamine, which has little if any effect centrally, was used to distinguish between central and peripheral effects of scopolamine.

\section{METHOD}

\section{Subjects}

The subjects were six male Long-Evans hooded rats, Simonsen Laboratories, weighing from 300 to $500 \mathrm{~g}$ at the beginning of the experiment. The rats were individually housed and reduced to $80 \%$ of ad-lib body weight. They were always fed after test sessions, and the amount of chow (Purina Lab Block) was adjusted for each animal to maintain its $80 \%$ weight. Water was continuously available in the home cages. One animal showed a toxic reaction, characterized by severe ataxia, to all doses of scopolamine and was, therefore, discarded.

\section{Apparatus}

The Plexiglas operant conditioning chamber, $23 \mathrm{~cm}$ long $\times$ $21 \mathrm{~cm}$ wide $\times 21 \mathrm{~cm}$ deep, was equipped with a Lehigh Valley liquid dipper. The cup on the dipper arm was modified to hold a very small amount of liquid $(.12 \mathrm{cc})$. The dipper access area measured $5.1 \mathrm{~cm}$ long $\times 3.8 \mathrm{~cm}$ wide $\times 5.1 \mathrm{~cm}$ deep, and was mounted flush with the front of the chamber, $2.5 \mathrm{~cm}$ to the left and $2.5 \mathrm{~cm}$ below the lever. The lever was $5 \mathrm{~cm}$ wide and protruded $2.5 \mathrm{~cm}$ into the chamber; approximately $30 \mathrm{~g}$ pressure was 
required to depress the lever. A light, mounted directly above the dipper access area, signaled operation of the dipper and presence of reinforcement.

The operant chamber was placed inside a sound- and lightattenuating box. Illumination was provided by two bulbs mounted on the wall of this acoustical chamber. A small exhaust fan was mounted on the outside of the acoustical chamber, and white noise $(70 \mathrm{~dB})$ was present inside. Standard electromechanical programming equipment was used to control the reinforcement schedules and to record barpresses.

\section{Procedure}

The animals were trained to barpress on a fixed-ratio-25 reinforcement schedule (FR25). After each set of 25 barpresses, the dipper became available for $5 \mathrm{sec}$, giving the animal access to a small amount $(.12 \mathrm{cc})$ of $32 \%$ sucrose solution. Each session lasted $1 \mathrm{~h}$ and was divided into the following segments: a 5-min $\mathrm{S} \Delta$ period during which no reinforcement was available; a 22.5-min period of FR25; a 5-min period of $\mathrm{S}^{\Delta}$; a 22.5 -min period of FR25; and, finally, a 5 -min $S^{\Delta}$ period. The $S^{\Delta}$ periods were signaled by the shutting off of the two houselights. When an animal was first placed in the chamber, the houselights were turned on for $2 \mathrm{sec}$ and then turned off, signaling the onset of the first $\mathrm{S} \Delta$ period. Animals were tested 5 days a week at approximately the same time each day. Drug treatments were begun for each animal when that animal's performance had stabilized according to the following criterion: barpress rates during the FR25 periods were within $10 \%$ of the mean rate during the three preceding sessions, with no upward or downward linear trends. Drugs were administered at 1 -week intervals provided baselines had remained stable during the intervening period. Each animal received each drug treatment once.

\section{Drug Treatments}

There were six drug treatments: three doses of scopolamine hydrobromide (supplied by Penick and Co., 100 Church St., New York, New York 10007), 1.2, 0.8, and $0.4 \mathrm{mg} / \mathrm{kg}$, two doses of scopolamine methylbromide, 1.2 and $0.8 \mathrm{mg} / \mathrm{kg}$, and physiological saline. All drugs were dissolved in physiological saline and administered intraperitoneally in a volume of $1 \mathrm{ml} / \mathrm{kg}$ approximately $30 \mathrm{~min}$ before testing. The order of drug treatment was randomized for each rat, with the restriction that neither scopolamine nor methyl scopolamine was administered in two consecutive sessions.

\section{RESULTS}

The mean response rates during nonreinforced (S $\Delta$ ) periods and fixed-ratio (FR25) periods are shown in Figure 1. The data are presented in terms of mean performance on methyl scopolamine (M) and mean performance on scopolamine $(\mathrm{SCO})$ because

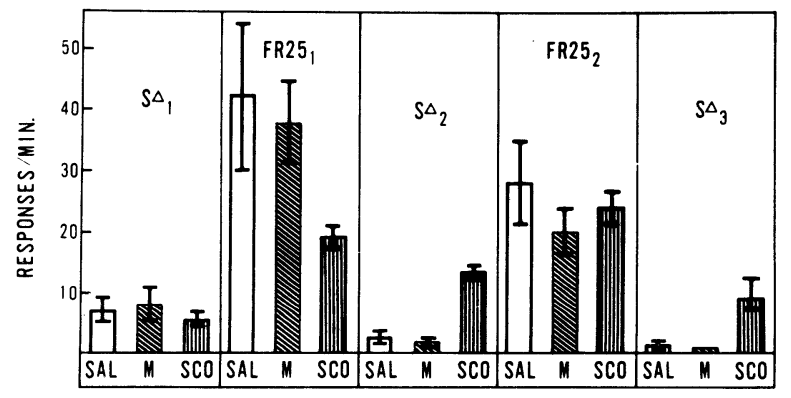

Figure 1. Mean rate of barpressing ( \pm SEm) during unreinforced $\left(S^{\Delta}\right)$ and fixed-ratio 25 (FR25) periods, under saline (SAL), methyl scopolamine (M), and scopolamine (SCO). there were no significant differences attributable to dosage, with one exception, discussed below.

\section{$\mathbf{S}^{\boldsymbol{\Delta}}$ Performance}

Comparison of response rates for the saline (SAL) treatment (Figure 1) for the three $S^{\Delta}$ periods shows a clear difference in normal (undrugged) response rates. During nondrugged or SAL sessions, animals typically showed some responding during the first $\mathrm{S}^{\Delta}$ period, but showed a virtually complete suppression of responding during the second and third $\mathrm{S}^{\Delta}$ periods. As Figure 1 shows, scopolamine, but not methyl scopolamine, caused the animals to respond through these later $S^{\Delta}$ periods. The data were analyzed using the Friedman analysis of variance by ranks (Siegel, 1956). The increased rates during $S_{2}^{\Delta}$ and $S_{3}^{\Delta}$ were both significant relative to control, with $\mathrm{X}_{\mathrm{r}}^{2}=9.1 \quad(\mathrm{p}<.01)$ and $\mathrm{X}_{\mathrm{r}}^{2}=8.4$ $(p<.01)$, respectively.

There was no significant difference between scopolamine and control treatments during $S_{1}^{\Delta}$ $\left(\mathrm{X}_{\mathrm{r}}^{2}=1.6\right)$, but this was the case in which one dosage difference was observed. The response rate was lower under $.4 \mathrm{mg} / \mathrm{kg}(1.48 \mathrm{R} / \mathrm{min})$ than under $.8 \mathrm{mg} / \mathrm{kg}$ $(7.04 \mathrm{R} / \mathrm{min})$ or $1.2 \mathrm{mg} / \mathrm{kg}(7.8 \mathrm{R} / \mathrm{min})$ and the difference was significant in the analysis of variance by ranks $\left(\mathrm{X}_{\mathrm{r}}^{2}=6.4, \mathrm{p}<.05\right)$. However, it would be difficult to interpret this difference since none of the doses differed significantly from control.

\section{Fixed-Ration Performance}

Comparison of the response rates during the fixedratio segments of the session show that scopolamine produced a significant decrease in response rate during FR25 $\left(\mathrm{X}_{\mathrm{r}}^{2}=7.6, \mathrm{p}<.05\right)$, but not during the FR25 $\left(\mathrm{X}_{\mathrm{r}}^{2}=2.8\right)$. Taken by itself, this result would seem to suggest that scopolamine decreased the work rate for food reinforcement, at least during FR25 . However, examination of the cumulative records showed that the effect was not so much a reduction in the actual rate of performance as a delay in the onset of barpress behavior. This effect is shown in Figure 2, which compares mean time to first reinforcement under scopolamine, methyl scopolamine, and saline. As the figure shows, animals under saline (SAL) began barpressing as soon as the houselights signaled the onset of the FR25 period; typically, they received the first reinforcement within seconds of the onset of the FR25 period. In contrast, when treated with scopolamine, animals explored the chamber and often did not receive a reinforcement until well into the period. As the figure shows, the increase in time to first reinforcement occurred following scopolamine, but not methyl scopolamine. An analysis of these data showed that the increase in time to first reinforcement was significant $\left(\mathrm{X}_{\mathrm{r}}^{2}=8.4, \mathrm{p}<.01\right)$.

Since the decrease in overall FR rates during FR25, 


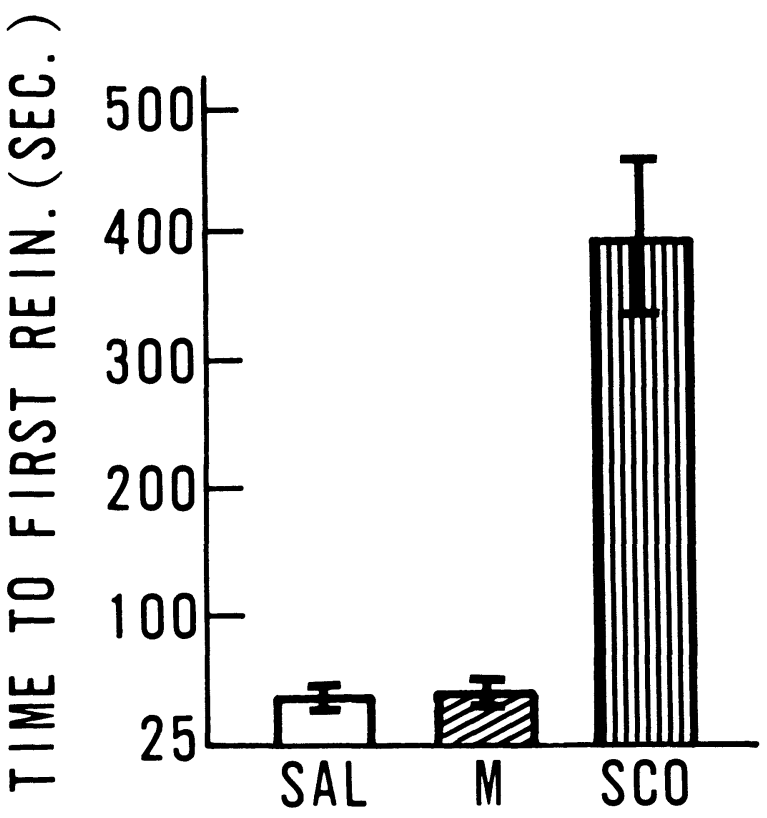

Figure 2. Mean time elapsed ( $\pm \mathrm{SEm}$ ) from onset of fixed-ratio 25 (FR25) period to first reinforcement under saline (SAL), methyl scopolamine (M), and scopolamine (SCO).

could be attributed to the delayed onset of barpressing, the question remained, did scopolamine alter the rate of performance for food reinforcement once the animal got started. Looking at response rate during FR25 2 (Figure 1), it is clear that response rates under scopolamine fall within the standard error of the mean for saline control periods; i.e., response rates were not significantly depressed by scopolamine during this second FR period. For additional information on this question, response rates were recalculated, correcting for the initial exploratory period by subtracting out time to first reinforcement. Under scopolamine, rate after first reinforcement was virtually identical to that under methyl scopolamine ( $\bar{M}=27$ and 28.9 responses $/ \mathrm{min}$, respectively) and there was no significant difference from that under saline $(\overline{\mathrm{M}}=\mathbf{3 5 . 6}$ responses $/ \mathrm{min})$.

Although the rate of barpressing after initiation was unchanged by scopolamine, the topography of responding on the FR25 schedule was changed (Figure 3). Under saline and methyl scopolamine, all of the animals showed typical step-like FR topography; i.e., bursts of 25 responses that produced reinforcement were followed by a pause (period of nonresponding), with resumption of responding occurring abruptly at a high rate. Under scopolamine, however, four of the five animals showed a change in topography under all three doses. The postreinforcement pause, characteristic of FR schedules, was eliminated or delayed, causing the curves to resemble those generated by variable ratio schedules.

\section{DISCUSSION}

Although rate of barpressing appeared to be depressed during FR25, the depression was attributable to a delay in the onset of barpress behavior. Comparisons of the time elapsed to first reinforcement showed that under scopolamine the animals took significantly longer to begin work on the FR schedule. Observations of the animals during these periods of delayed onset revealed that they were moving around the experimental chamber in what appeared to be exploratory behavior. This finding is consistent with earlier reports that anticholinergic drugs increase exploratory behavior or cause animals to behave as though they had not been habituated to the apparatus (Carlton, 1969).

For the effects of scopolamine on food-reinforced behavior per se, it is interesting to look at performance after this initial period of heightened exploration has elapsed. There was no significant difference among treatments in rate of barpressing after first reinforcement. In other words, once the animals had overcome the initial exploratory tendencies under scopolamine, their work rate for food reinforcement appeared normal.

The present results bear on earlier findings with anticholinergic drugs and food intake. Since anticholinergic drugs have been known to decrease food intake (Miczek, 1973; Schmidt et al., 1958), it is pertinent that barpress rates during the FR25 periods were not significantly depressed by scopolamine. This result is consistent with Stein's (1963) conclusion that the decrease in food intake following anticholinergic drugs is attributable to peripheral actions of the drugs.

It is equally significant that FR25 rates were not increased by scopolamine. Increased rates might have

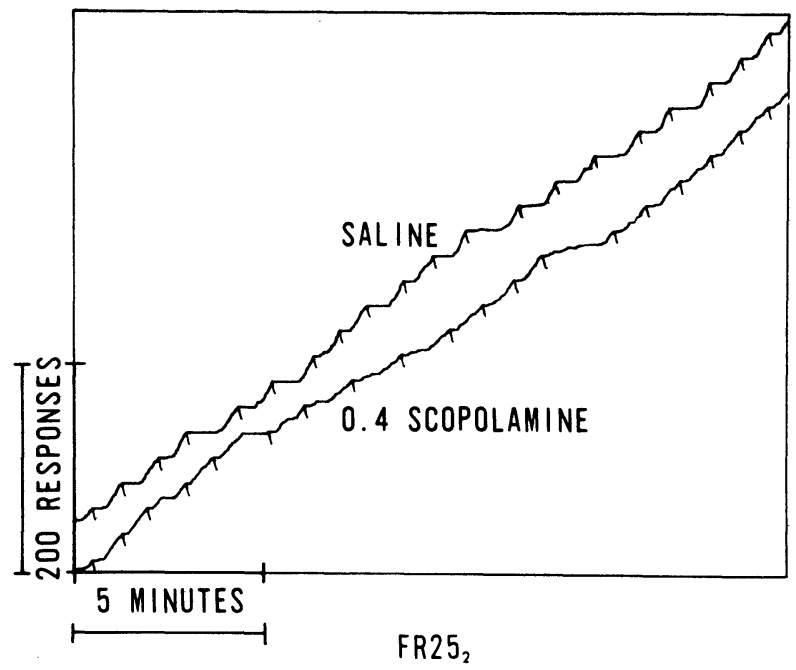

Figure 3. Representative cumulative records of $\mathrm{FR25}_{2}$ barpressing; shows typical saline FR25 performance and the altered topography produced by scopolamine $(0.4 \mathrm{mg} / \mathrm{kg})$. 
been expected since direct chemical stimulation of the brain had implicated a cholinergic system in the decrease of food intake (Singer \& Kelly, 1972). Also, previous work with systemic injections had raised the possibility that scopolamine increased food-reinforced behavior (Plotnik et al., 1974). The present results argue against the possibility that anticholinergic drugs facilitate food-reinforced behavior.

Although scopolamine did not affect the overall rate of performance after first reinforcement and during FR25, a drug effect was apparent in the topography of FR performance. Under scopolamine, the animals no longer showed the typical step-like FR responding. Rather, the barpress curves took on a smoother appearance, in which the postreinforcement pause was either delayed or omitted. A drug effect was also apparent during the unreinforced or $\mathrm{S}^{\Delta}$ segments of the schedule. During saline and methyl scopolamine sessions, there was a substantial suppression of responding in the second and third $\mathrm{S}^{\Delta}$ periods. Under scopolamine, the animals failed to show a suppression during these $S^{\Delta}$ periods and, instead, emitted a significant number of unreinforced responses. This finding is consistent with earlier work showing that cholinergic blockade caused animals to respond through $\mathrm{S}^{\Delta}$ periods (Carlton, 1969; Herrnstein, 1958).

In conclusion, the dose range used in the present research was clearly an effective one and was comparable to those used in the literature. The results of the present research are consistent with Carlton's (1969) formulation of a cholinergic system involved in the inhibition of punished or unrewarded behavior. According to this view, anticholinergic drugs should disinhibit exploratory behaviors and behaviors that have been actively suppressed, but should have little effect on behaviors that are maintained by biologically significant rewards such as food. In the present research, scopolamine did not significantly alter the FR rates for food reinforcement. It did, however, cause a significant increase in time to first reinforcement, which suggests disinhibition of exploratory behavior. It also caused increased responding through $\mathrm{S}^{\Delta}$ periods, which suggests disinhibition of suppressed behavior. In both cases, the disinhibition occurred with scopolamine but not methyl scopolamine, indicating that the effects of scopolamine were attributable to actions of that drug on the central nervous system.

\section{REFERENCES}

Cartton, P. L. Brain acetylcholine and inhibition. In J. T. Tapp (Ed.), Reinforcement and behavior. New York: Academic Press, 1969. Pp. 286-327.

Grossman, S. P. Direct adrenergic and cholinergic stimulation of hypothalamic mechanisms. American Journal of Physiology, 1962, 202, 872-882.

HeRRNSTEIN, R. J. Effects of scopolamine on a multiple schedule. Journal of the Experimental Analysis of Behavior, 1958, 1. 351-358.

LeAton, R. N., \& KREIndLER, M. Effects of physostigmine and scopolamine on operant brightness discrimination in the rat. Physiology and Behavior, 1972, 9, 121-123.

MiCZEK, K. A. Effects of scopolamine, amphetamine and benzodiazepines on conditioned suppression. Pharmacology, Biochemistry and Behavior, 1973, 1, 401-411.

Plotnik, R., Mollenauer, S., \& SNYder, E. Fear reduction in rat following central cholinergic blockade. Journal of Comparative and Physiological Psychology, 1974, 86, 1074-1082.

Schmidt, H., Moak, S. J., \& Van Meter, W. G. Atropine depression of food and water intake in the rat. American Journal of Physiology, 1958, 192, 543-545.

Siegel, S. Nonparametric statistics. New York: McGraw-Hill, 1956.

Singer, G., \& Kelly, J. Cholinergic and adrenergic interaction in the hypothalamic control of drinking and eating behavior. Physiology and Behavior, 1972, 8, 885-890.

STEIN, L. Anticholinergic drugs and the central control of thirst. Science, 1963, 139, 46-48.

WaGMAN, W. D., \& MAXEY, G. C. The effects of scopolamine hydrobromide and methyl-scopolamine hydrobromide upon the discrimination of interoceptive and exteroceptive stimuli. Psychopharmacologia (Berl.), 1969, 15, 280-288.

Whitehouse, J. M. Effects of atropine on discrimination learning in the rat. Journal of Comparative and Physiological Psychology, 1964, 57, 13-15.

(Received for publication October 21, 1975; revision accepted July $21,1976$. ) 